\title{
Géographie historique, peuplement et terroirs dans la région du Hodna occidental au Moyen Âge
}

\author{
Mohamed Meouak \\ Cadix
}

\begin{abstract}
Based on a critical lecture of Medieval Arabic historical and geographical sources, this study deals with three points mainly centred on settlement topics. The first point consists of a description of the Western Hodna within the geographical history of the Central Maghreb. The second question offers a list of the main sites of Western Hodna through the Medieval Arabic sources with the whole settlement's Arabic vocabulary. The third part tries to give some observations on the modalities of settlements, the tribal impact on the settlements and the problem of the types of settlements: village (qarya) and fortress (hisn). The last part is a summary of the study with several suggestions for further research in relation to the studied matters like historical geography and rural economy.
\end{abstract}

Keywords: Medieval Central Maghreb; Western Hodna; settlements; tribes; fortress; village.

\section{Introduction}

L'objectif de cette recherche, déjà en phase d'élaboration avancée, est de mettre en relief un certain nombre de caractères et spécificités 
relatifs aux territoires et aux modes de peuplement d'une région précise du Maghreb central, à savoir la partie occidentale du Hodna (en arabe Huḍna). Ce travail se base essentiellement sur le dépouillement des principaux textes géographiques arabes du Moyen Âge mais il tient compte également de l'apport de quelques sources historiques et littéraires. Outre les genres textuels mentionnés, on mettra aussi à profit les productions bibliographiques anciennes et récentes sur les questions de géographie, de peuplement et de territoire. Pour tout cela, il nous a paru également nécessaire de fournir les données textuelles sous forme de notices tirées des sources arabes puis traduites en français. Cette préoccupation méthodologique est étroitement liée à notre conception de l'analyse historique des sources : essayer de cerner correctement les problèmes posés dans notre travail grâce à l'outil textuel afin de mieux comprendre les enjeux du sujet historique ${ }^{1}$.

L'étude des noms de lieux, comme élément fondamental pour la compréhension des terroirs et des paysages, constitue de toute évidence un moyen utile pour la compréhension des modalités de peuplement des diverses régions du Maghreb au Moyen Âge. Le contact des langues serait sans nul doute un élément à prendre en compte lorsque l'on veut mesurer les raisons de tel type d'aménagement des terroirs ou de tel fait de construction modifiant le paysage naturel. Ces langues comprises dans leur contexte historique et qui seront l'objet d'une étude ultérieure, sont surtout l'arabe, le berbère, le latin d'Afrique et le grec avec des variantes les caractérisant ${ }^{2}$. Grâce à la toponymie, il est possible de se faire une

1 Sur le Hodna et ses principaux traits morphologiques, voir Despois, 1942, pp.196-206 offrant des éléments de géographie mis en comparaison avec le Tell et les bordures sahariennes. Pour le Hodna dans l'histoire (fin de l'époque antique et Moyen Âge), on peut lire Idris, 1962, II, pp.482-486, 491 ; Forstner, 1979, pp.54, 61, 66, 96, 98, 102, 172, 185, 188, 197 ; Dachraoui, 1981, pp. 94, 152, 194, 199, 211, 240, 271, 347-349, 353, 368, 378, 381 ; Chapoutot-Rémadi, 1980, pp.12-13 ; Pentz, 2002, p.162 et Valérian, 2006, pp.137-140.

2 Parmi l'abondante bibliographie sur le sujet, voir Lengrand, 2005, pp.119-121 sur les langues d'Afrique documentées dans l'Antiquité tardive et les observations suggestives de Desanges, 2005, pp.19-21 sur la phonétique historique de la toponymie d'Afrique du Nord ; pour le berbère, consulter Chaker, 1981, pp.31-37 ; idem, 1983, pp.139-143, et Meouak, 2010 (pp.193- 
idée, même approximative, des principaux traits qui présidèrent au peuplement des divers territoires du Maghreb. Et il est bien entendu évident que l'intervention de la géographie en tant que science constitue un instrument fondamental car elle permet de mieux saisir les changements de la morphologie des terrains, ou dit d'une autre manière l'intervention anthropique sur la terre. Les noms de lieux entretiennent souvent une relation étroite avec des situations morphologiques et topographiques spécifiques, et ils sont susceptibles de montrer à quel point les langues du Maghreb, du moins l'arabe et le berbère, sont parfois des langues de départ parfois des langues d'arrivée capables de fournir un autre regard sur le comment les individus appréhendaient leur entourage naturel ${ }^{3}$.

Avant d'entrer dans le coeur du sujet, il faut cependant avertir le lecteur que pour le Maghreb central, les géographes et les historiens arabo-musulmans dans leur ensemble sont malgré tout peu loquaces quant aux informations qu'ils seraient susceptibles de fournir sur les structures du territoire et son peuplement au haut Moyen Âge par exemple. Le problème de la relative indigence documentaire se pose donc avec acuité lorsque l'on essaie de reconstituer les tissus socioéconomiques et les formes d'occupation du territoire. Malgré ce qui vient d'être dit, la présente étude essaiera de dresser un tableau, si possible précis, des principaux modes d'occupation et de structuration des terroirs dans une région spécifique ${ }^{4}$. Pour ce faire, nous diviserons notre étude en quatre ensembles : la situation du Hodna dans l'espace géographique maghrébin, la mise au jour d'un petit corpus de quatorze sites du Hodna occidental et documentés dans les textes arabes, des remarques générales sur les modalités de peuplement de la région et des conclusions qui essaieront de faire le point sur les résultats obtenus et certains problèmes non abordés dans le détail mais qu'il

198) sur la langue berbère dans les sources géographiques arabes du Moyen Âge.

3 On pourra se faire une idée de la problématique du berbère en contact avec l'arabe au Moyen Âge en lisant Meouak, 2006b, pp.329-330 et idem, 2008, pp.56-58.

4 Afin de prendre connaissance des principales caractéristiques géographiques, tribales et agricoles du Hodna occidental au Moyen Âge, voir Meouak, 2009, pp.120-134. 
sera nécessaire de poser avec précision pour tenter de les résoudre ultérieurement.

\section{Le Hodna dans la géographie historique du Maghreb médiéval}

On dit souvent que le Hodna est une aire géographique déprimée des hautes plaines de l'Algérie, au pied des monts Ouennougha (Wānnūgà), du Hodna et du Belezma, et ouverte vers le sud-est sur la région pré-saharienne du Zāb de Biskra. Le grand Hodna s'étend sur près de $8600 \mathrm{~km}^{2}$ et comprend surtout les ensembles suivants : les collines du Djerr au nord et à l'est, de vastes plaines alluviales partiellement innondées par les crues des oueds descendus des zones montagneuses, une grande $s a b \underline{h} a$ de quelques $760 \mathrm{~km}^{2}$ et, au sud, une région sablonneuse appelé le R'mel. Le pays est en règle générale très chaud en été et très sec (de 150 à $300 \mathrm{~mm}$. de pluie annuelle) et il constitue une véritable steppe pré-désertique privée de la culture de l'alfa. Ce grand territoire est assez riche en eau grâce aux sources calcaires, aux crues importantes mais très irrégulières des oueds, notamment ceux de Barika, Bitham, Ksob, Leham, Magra et Selman ainsi qu'aux nappes en partie artésiennes du sous-sol ${ }^{5}$.

Les monts de l'Aurès, du Belezma, du Hodna et des Ouennougha forment un arc de cercle qui dressent une limite géographique d'une singulière précision du point de vue physique comme du point de vue des opportunités économiques, entre les régions méditerranéennes du Tell et les plaines désertiques des Ziban et du Hodna. Il est tout à fait extraordinaire que cet arc montagneux n'ait pas servi de frontière humaine ou politico-administrative qu'il semblait, à première vue, imposer. Il est admis que les populations des montagnes ont souvent étendu leur domaine économique sur la bordure des plaines et c'est ainsi que les massifs montagneux ont plutôt joué un rôle de refuge aux tribus vaincus ou refoulés des piémonts. Le mode de vie nomade a souvent envahi les hautes plaines du Tell qui ont servi de pâturages d'été aux pasteurs des steppes et du désert. À l'inverse, la vie sédentaire semble être descendue tout au long des cours d'eau originaires du Tell et autour des sources en bordure du pays nomade. La frontière politique qui était généralement utilisée pour couper

5 Despois, 1953, pp.15-94 et idem, 1958, pp.10-11, 16-17. 
l'Algérie en deux blocs précis, séparant une Algérie dite orientale, soumise aux influences de Carthage, de Kairouan ou de Tunis, et une Algérie occidentale dépendante des capitales et des dynasties du Maghreb occidental ou de Tlemcen, n'a jamais emboîté le pas à la limite climatique, orographique et économique que la nature et le relief paraissaient imposer aux hommes. Elle est en fait toujours passée à l'Ouest et au Sud du Hodna comme des Ziban de Biskra, rattachant donc ces deux régions à l'Ifrīqiya ${ }^{6}$.

\section{Corpus des principaux sites du Hodna occidental d'après les sources arabes du Moyen $\hat{A ̂ g e}^{7}$}

1) al-Masīla (aujourd'hui M'sila) ${ }^{8}$

Al-Muqaddasī, 1950 :

texte arabe, p.8 : wa-l-Zāb madīnatuhā al-Masīla wa-lahā Maqqara [...].

traduction, p.9 : «Le Zāb dont la capitale est M'sila avec la ville de Maqqara $[\ldots] »$.

6 Despois, 1942, pp.214-218 et idem, 1953, pp.99-138.

7 Avant d'entrer en matière, précisons bien que ce corpus n'a pas la prétention d'être exhaustif. Indiquons en outre que les notices ont été présentées par ordre chronologique des sources, de la plus ancienne à la plus récente ; les renvois aux sources se font d'après la date d'édition (exemple : al-Muqaddasī, 1950, ...).

8 La question de la fondation de M'sila (al-Masīla / al-Muhammadiyya) au 4 e $/ \mathrm{X}^{\mathrm{e}}$ siècle constitue encore un problème fondamental parmi les débats relatifs à l'histoire médiévale du Maghreb central. Grâce aux notices fournies dans les pages suivantes, le lecteur déduira que le fait d'être confronté à diverses versions fournies par la documentation arabe entraîne de véritables difficultés d'interprétation quant à la date et au site de création ainsi qu'aux circonstances politiques qui y présidèrent. Sur ce site, voir Brunschvig, 1940, I, pp.290-291 ; Golvin, 1957, pp.20-21, 40-42, 53-54, 80-81, 100-103, 106-109, 118-119, 138143 ; Idris, 1962, I, pp.21-24, 92-95, II, pp.484-486 ; Bencheneb, 1968, pp.1215 ; Talbi, 1966, pp.590, 669 ; Kurio, 1973, pp.6, 67, 122 ; Massiéra, 1974, pp.179-184 ; Forstner, 1979, pp.185-187 ; Dachraoui, 1981, pp.164-165, 173, $180,196,199-200,203,206,208,230,238-240,270-272,316,319,349,353-$ 354, 373, 380 ; Cambuzat, 1986, II, pp.157-164 ; Souidi, 1996, pp.52, 71, 79, 171-172, 186, 189 ; Hasan, 1999, I, pp.35, 36, 102, 109, 110, 209, 325, 327 et Valérian, 2006, pp.138-139, 148-149, 168-169. 
texte arabe, p.28 : wa-l-Zāb madīnatuhā al-Masīla wa-hiya ayḍan nāhiya 'alā ma wașafnā madkūra fì l-iqlīm gaayr an Țanğa ăgall [...].

traduction, p.29 : «Le Zab, dont la capitale est M'sila d'après la description qu'on nous en a faite, est également une région renommée au Maghreb, mais celle de Tanger est plus importante [...]».

Ibn Hawqal, 1938-1939 :

texte arabe, I, p.85 : wa-min Maqqara ilā l-Masīla marhala wa-hiya madīna ${ }^{t}$ muhdața istahdatahā 'Alī b. al-Andalusī ahad hadam min āl 'Ubayd Allāh wa-'abìduhum; wa-'alayhā sūr hașinn min țūb wa-lahā wādin yuqālu lahu Sahur fìhi mā' 'az̄im munbasit 'alā wağh al-arḍ wa-laysa bi-l-'amīq [...].

traduction : " De Magra à M'sila, il y a une étape, et c'est une ville fondée récemment par 'Alī b. al-Andalusī, un des serviteurs et esclaves de la famille de 'Ubayd Allāh; il y a un mur solide en briques ; une rivière y coule, l'oued Sahur, au débit abondant, qui a une large nappe d'eau mais qui est peu profonde ».

\section{Al-Bakrī, 1965 :}

texte arabe, p.59 : wa-hiya madīna fì bisāt min al-ard 'alayhā sūrān baynahumā ğadwal mā' ' ğāra yastadīru bi-l-madīna wa-lahu manāfid tusqā minhà 'inda al-h̄àğa wa-li-l-madīna aswāq wa-hammāmāt wahawlahā basātīn kațīra wa-yağūdu indahum al-quṭn wa-hiya kațīa al-lahm rahiș̣a al-sa'r.

traduction, p.124: "C'est une ville située dans une plaine, entourée de deux murailles, entre lesquelles se trouve un canal d'eau vive qui fait le tour de la ville. Par le moyen de vannes, on peut tirer de l'eau pour l'irrigation des terres. Dans la ville, il y a des marchés et des bains, et, à l'extérieur, de nombreux jardins. On y récolte beaucoup de coton et la viande est bon marché ». 
Al-Idrīsī, 1983 :

texte arabe, p.108 : al-Masīla : țumma ilā l-Masīla marhalatān ; wa-

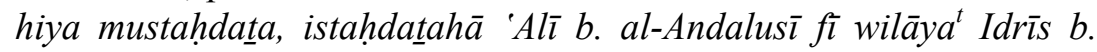
'Abd Allāh b. al-Hasan [b. al-Hasan] b. al-Husayn b. 'Alī b. Abī Ṭālib radiya Allāh 'anhu ; wa-hiya 'ämira fì basìt min al-arḍ ; wa-lahā mazāri' mumtadda aktar mimmā yahtāğu ilayhi ; wa-li-ahlihā sawā'im hayl wa-aḡnām wa-abqār wa-ğannāt wa-'uyūn wa-fawākih wa-buqūl wa-luhūm wa-mazāri' quṭn wa-qamh wa-ša'īr ; wayaskunuhā min al-Barbar Banū Birzāl wa-Zandāğ wa-Hawwāra waSadrāta wa-Mazāta ; wa-hādihi al-madīna ayḍan 'āmira bi-l-nās wal-tuğğār ; wa-hiya 'alā nahr fîhi mā' kațìr mustanbit 'alā wağh alard ; wa-laysa bi-l-'amīq ; wa-huwa 'adb ; wa-fihi samak șagìir, fìhi turuq humr hasana; wa-lam yura fì bilād al-ard al-ma'mūra samak alā șifatihi ; wa-ahl al-Masīla yaftahirūna bihi ; wa-yakūn miqdār hādāa al-samak min šibr ilā mā dūnihi ; wa-rubbamā uștīida minhu alšay' al-kațīr ; fa-uhtumila ilā qal 'a ${ }^{t}$ Ban̄̄ Hammād wa-baynahumā atnnā' 'ašar $m \bar{\imath} \bar{l}^{\bar{a} n}$.

traduction, p.100 : «Puis jusqu'à M'sila, il y a deux étapes. Elle fut fondée par 'Alī $b$. al-Andalusī, sous le règne d'Idrīs b. 'Abd Allāh $b$. al-Ḥasan [b. al-Ḥasan] b. al-Ḥusayn b. 'Alī b. Abī Ṭālib, que Dieu soit satisfait de lui. M'sila est une ville moderne, populeuse et située sur un terrain plat. Elle a de vastes exploitations agricoles dont la production excède les besoins des habitants. Ces derniers possèdent des bestiaux : équidés, ovins, bovins ; ils ont des jardins irrigués qui produisent des fruits et des légumes ; ils ont de la viande ; ils ont des plantations de coton, de blé et d'orge. Parmi les Berbères qui habitent à M'sila, il y a les Banū Birzāl, Zandāğğ, Hawwāra, Șadrāta et Mazāta. Cette ville est également peuplée d'autres ethnies et de marchands. Elle est sur un canal dont l'eau coule en abondance, à ciel ouvert, qui est peu profond, qui est limpide et qui contient de beaux petits poissons rayés de rouge, comme on en trouve nulle part ailleurs sur la surface de la terre. Les gens de M'sila en sont fiers. Les dimensions de ce poisson sont d'un empan et plus. Parfois, on en pêche une grande quantité qu'on va vendre à la qal'a des Banū Ḥammād, à douze milles de là ». 
Al-Istibṣār, 1958 :

texte arabe, pp.171-172 : madīnat al-Masīla : aqrab bi-qal' $a^{t}$ Hammād min bilād al-Zāb, madīnat al-Masīla wa-hiya fì basìt min alard 'alā nahr kabīr yusammā bi-Sahur, wa-manba'uhu min madīnat al-Ġadīr wa-qad dakarnāhu, madīnat al-Masīla ahdațahā Abū lQāsim Ismā'īl b. 'Ubayd Allāh al-Šš ‘̀ mundu sana 313 wa-kāna mutawallì li-binā'ihā 'Alī b. Hamdūn b. Sammāk al-ma 'rū fi-Ibn alAndalusī [...] wa-madīnat al-Masīla katīirat al-nahl wa-l-basātīn tašuqqahā ğadāwil al-miyāh al-'aḍba, wa-kānat madīna' 'azīma 'alā nazar kabìr, wa-hawā̄īhà qabā'il kațīra min al-Barbar min 'Ağīsa wa-Hawwāra wa-Ban̄̄ Birzāl.

traduction : «La ville de M'sila, qui est plus proche de la qal'a des Ḥammād que du pays de Zāb, se trouve à l'intérieur des terres sur une rivière importante nommée Sahur ; elle prend sa source dans la ville de Ghdir dont nous avons déjà parlé. La fondation de la ville de M'sila, due à Abū l-Qāsim Ismā‘îl b. 'Ubayd Allāh al-Šsî̀î, remonte à l'année 925 et il confia le soin d'y veiller à Alī b. Hamdūn b. Sammāk connu sous le nom d'Ibn al-Andalusī [...] Dans les environs de M'sila, il y a beaucoup de palmiers ainsi que des vergers arrosés par des ruisseaux d'eau douce ; c'est une ville importante, chef-lieu d'un canton étendu et dont les alentours sont occupés par plusieurs tribus berbères des 'Ağ̄isa, des Hawwāra et des Banū Birzāl ».

Ibn Hammād, 1984, p.24 : sur la fondation de M'sila et l'existence de deux portes : bāb al-umūr et bāb al-Qāsimiyya; pp.25, 31, 36, 38, 40 : simples mentions du nom de M'sila.

Yāqūt, 1979-1986 :

texte arabe, IV, p. 130 : al-Masīla : madīnat al-Magrib tusammāa alMuḥammadiyya inhtațtahā Abū l-Qāsim Muhammad b. al-Mahdī fì 315 wa-huwa yawma'id walì 'ahd abīhi.

traduction : «M'sila : ville du Maghreb appelée Muhammadiyya ; Abū l-Qāsim Muhammad b. al-Mahdī en a tracé le plan en 927 et c'est à cette époque qu'il devint le prince héritier de son père ». 
Ibn Haldūn, 2003, pp.132, 136 et 137 : simples mentions du nom du site (al-Masīla).

Ibn Rašīq al-Qayrawānī, 1991 :

texte arabe, p.140 : al-Muhammadiyya min ard al-Zāb.

traduction : " Muhammadiyya dans le territoire du Zāb ».

texte arabe, p.352: baldat al-Muhammadiyya.

traduction : «Ville de Muḥammadiyya ».

Idrīs 'Imād al-Dīn, 1985 :

texte arabe, p. 217 : wa-umira 'alayhi al-salām bi-binā' madīnat alMasīla wa-aqāma 'Alī b. Hamdūn li-binā'ihā wa-amarahu an

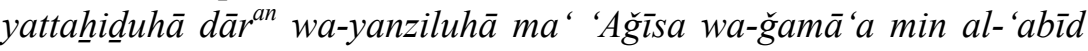
wa-hiya ard fìhā miyāh ğāriya wa-fuhūs kațīra wāsi 'a al-zar'.

traduction : «On y ordonna de faire régner la paix avec la construction la ville de M'sila ; c'est 'Alī b. Hamdūn qui dirigea sa construction et on lui ordonna d'y prendre demeure et d'y habiter avec les 'Ağ̄isa et l'ensemble des esclaves ; c'est une terre où il y a des cours d'eau vive avec de nombreuses plaines spacieuses pour l'agriculture ». 
2) Maqqara (antique MACRI et aujourd'hui Magra) ${ }^{9}$

Al-Ya'qūbī, 1892 :

texte arabe, p.351 : wa-madīna yuqālu lahā Maqqara lahā hușūn kațīra wa-l-madīna al- 'uzmāa ahluhā qawm min Bañ̄ Dabba wa-bihā qawm min al-'Ağam wa-hawlahā qawm min al-Barbar yuqālu lahum Ban̄̄ Zandāğ wa-qawm yuqālu lahum Ban̄̄ Krbrh wa-qawm yuqālu lahum Sadrāta.

traduction : «Et la ville qui est appelée Magra possède de nombreuses forteresses ; c'est une des villes les plus importantes ; sa population est constituée de la tribu des Banū Dabba, d'une tribu de "non Arabes" (al-'A ğam $)^{10}$; dans ses environs, il y a la tribu berbère des Banū Zandağ, une tribu appelée Banū Krbrh et une tribu appelée Sadrāta ».

9 Sur ce site, voir Gsell, 1911, feuille 26, $\mathrm{n}^{\text {os }} 110-111$; Diehl, 1896, p.252 sur CELLAE, site très proche de Magra et doté d'un fortin d'époque byzantine ; Brunschvig, 1940, I, pp.291-292 ; Baradez, 1949, pp.91, 348 ; Golvin, 1957, pp.19, 86, 100, 106, 119, 137, 139, 143-144 ; Idris, 1962, I, pp.22, 112, 156, II, pp.484, 522 ; Forstner, 1979, pp.47, 67, 75, 120, 188, 197, 219, 308 ; Dachraoui, 1981, pp.196, 380 ; Cambuzat, 1986, II, pp.144-147 ; Hasan, 1999, I, pp.109, 110, 325, 327 ; Benseddik, 1999, p.94 signale le site de Macri sur le limes de la Maurétanie Césarienne ; Modéran, 2003, pp. 92, 382, 395 évoque le toponyme antique de Macri, et Valérian, 2006, pp.138-139, 168.

10 À propos de la notice d'al-Ya'qūbī, il est utile de signaler que l'orientaliste polonais Tadewsz Lewicki (Lewicki, 1953, p.426) avait déjà détecté la présence de quelques établissements romano-chrétiens en Numidie du sud débordant la frontière ouest de cette ancienne province et atteignant ainsi la portion méridionale de la Maurétanie Sitifienne où, au nord-ouest du Chott el-Hodna, on trouve une colonie peuplée de 'A ğam dans la localité musulmane de Magra qui fait partie du Zāb. La problématique relative aux divers sens du terme 'Ağam n'a cessé d'alimenter les débats au ton parfois polémique. Contrairement au sens de "Persans" donné au vocable dans certains espaces géohistoriques, c'est sur la base du contexte culturel et linguistique africano-berbère que nous choisissons de rendre le mot de 'Ağam par "non Arabes", c'est-à-dire ceux qui étaient Africains et donc ne parlant pas la langue arabe. Mais nous sommes bien conscients que cette question mériterait une étude plus longue basée d'abord sur le dépouillement exhaustif des sources arabes et latines. 
Al-Muqaddasī, 1950 :

texte arabe, p.8 : wa-l-Zāb madīnatuhā al-Masīla wa-lahā Maqqara $[\ldots]$.

traduction, p.9 : «Le Zāb dont la capitale est M'sila avec la ville de Magra [...]».

Ibn Ḥawqal, 1938-1939 :

texte arabe, I, p.85 : wa-min Tubna ilā Maqqara : manzil fïhi aydan marșad marhala.

traduction : "Puis de Tubna jusqu'à Magra, une étape : il y a une station et également un poste de guet ».

Al-Bakrī, 1965 :

texte arabe, p.51 : wa-min Tubna ilā madīnat Maqqara wa-huwa balad kabīr diu timār wa-anhār wa-mazāri .

traduction, pp.110-111 : «De Tobna jusqu'à la ville de Magra ; c'est une grande cité possédant des arbres fruitiers, des ruisseaux et des champs cultivés ».

Al-Idrīsī, 1983 :

texte arabe, p.119 : Maqqara: wa-tahruğu min al-Masīla ilā Maqqara marhala ; wa-hiya madīnat șagì̃ra, wa-biha mazāri' wa-hubūb ; waahluhā yazra'üna al-kattān ; wa-huwa 'indahum kațīr ; wa-min Maqqara ilā Tubna marḥala.

traduction, p.112: «La route débouche de M'sila et va jusqu'à Magra en une étape. C'est une petite ville entourée de terres de culture et de céréales. Ses habitants cultivent le lin en abondance. De Magra jusqu'à Tobna, il y a une étape ». 
Yāqūt, 1979-1986 :

texte arabe, V, p.175 : Maqqara : wa-Maqqara madīna bi-l-Magrib fi barr al-Barbar qarība min qal 'a ${ }^{t}$ Ban̄̄ Hammād baynahā wa-bayna Tubna țamāniya farāsih wa-kāna bihā mașlaḥa bi-l-sulțān ḍābița li-ltarīq.

traduction : «Magra : Magra est une ville du Maghreb sur le territoire des Berbères proche de la qal 'a des Banū Hammād ; entre elle et Tobna, il y a quatre-vingt parasanges ; il y a une station contrôlant la route ».

Ibn Maryam, 1908 :

texte arabe, p.155: Maqqara : qarya min qurā bilād al-Zāb min a 'māl Ifrīqiya.

traduction : «Magra, village parmi les villages de la région du Zāb dans les districts d'Ifrīqiya ».

Ibn al-Qāộ̄, 1970-1972 :

texte arabe, II, p.43 : nisba ilā Maqqara qarya bayna al-Qayrawān wa$l-Z \bar{a} b$.

traduction : «Nisba en relation avec Magra, village entre Kairouan et le $Z \bar{a} \mathrm{~b} »^{11}$.

Ibn Haldūn, 2000-2001 :

texte arabe, VI, p.46 : bi-l-Hușna (Huḍna) wa-hiya Niqāwus waMaqqara wa-l-Masīla.

traduction : «Dans le Hodna qui correspond à N'gaous, Magra et M'sila ».

11 Cette information est fournie au cours de la biographie d'un savant appelé Muḥammad b. Muḥammad b. Aḥmad b. Abī Bakr b. Yaḥyā al-Qurašì alTilimsānī al-Maqqarī (vers 759/1357). 
texte arabe, VI, p.588 : wa-qurā l-Hușna (Huḍna) : Maqqara waNiqāwus wa-l-Masīla.

traduction : «Les villages du Hodna sont N'gaous, Magra et M'sila ».

Idrīs 'Imād al-Dīn, 1985 :

texte arabe, p.393 : bi-mawḍi' yuqālu lahu Maqqara.

traduction : «Dans un endroit appelé Magra » 12.

Al-Maqqarī, 1988 :

texte arabe, V, p.205 : wa-hiya Maqqara min Zäb Ifrīqiya.

traduction : «C'est Magra dans le Zāb d'Ifrīqiya ».

texte arabe, V, p.280 : wa-Maqqara [...] qarya min qurā bilād al-Zāb min a 'māl Ifrīqiya.

traduction : «Magra [...] village parmi les villages de la région du Zāb dans les districts d'Ifrīqiya ».

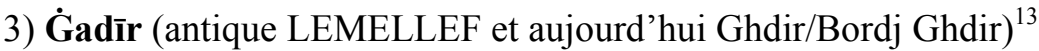

Al-Muqaddasī, 1950 :

texte arabe, p.6 : wa-ammā Tāhart fa-hiya ism al-qașaba ayḍdan wamin mudunihā [...] Gadìr al-durū ).

traduction, p.7 : «Quant à Tahert, ce nom s'appliquant également à la

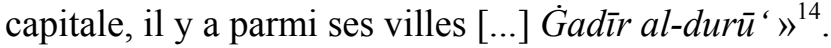

12 Simple mention du site de Magra au cours de laquelle on signale que l'imām alDağğāl y passa une nuit.

13 Sur ce site, voir Gsell, 1911, feuille 25, no 3 ; Diehl, 1896, p.255 ; Idris, 1962, II, pp.478, 504, 658 ; Forstner, 1979, pp.47, 177, 180, 184, 302 ; Dachraoui, 1981, p.200 ; Cambuzat, 1986, II, pp.103-106 ; Kehoe, 1988, p.212 sur Lemellef comme centre de production agricole, et Laporte, 1999, p.213 situant Lemellef à la frontière occidentale extrême de la Maurétanie Sitifienne avec la Maurétanie Césarienne. 


\begin{abstract}
Al-Bakrī, 1965 :
texte arabe, p.54 : wa-minhā ilā madīnat al-Ġadīr tah̆ruğu minhu 'uyūn nahr Sahur wa-huwa nahr al-Masīla wa-huwa al-ma'rüf binahr al-riy'īs.
\end{abstract}

traduction, p.115 : «De là jusqu'à la ville de Ghdir là où jaillisent les sources de la rivière Sahur qui est la rivière de M'sila et qui est plus connue sous le nom de rivière du chef $»^{15}$.

texte arabe, pp.59-60 : wa-nahr Sahur allad̄i 'alayhi madīnat alMasīla munba' 'ațhu min 'uyūn dāhil madīna ${ }^{t} \dot{G} a d \bar{i} r$ Wārrū, wa-hiya

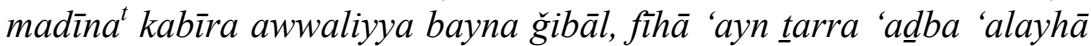

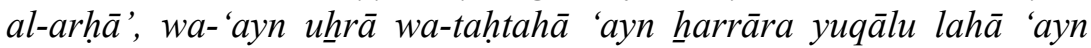
Mahlad tağtami 'u fìhā wa-min hunāka munba'at nahr Sahur, wa-bimadīnat al-Gadīr gāmi ' wa-aswāq 'āmira wa-fawākih kațīra, wa-hiya rahīṣa al-ța 'am wa-l-laḥm wa-ğamī' al-timār, qințār 'inab fìha bidirham, wa-sukkānuhā Hawwāra ya 'tadūna fì sittīn alf ${ }^{\text {an }}$.

traduction, pp.125-126 : «La rivière Sahur, près de laquelle M'sila est située, a ses sources dans l'intérieur de Ġadīr Wārrū, grande et ancienne ville entourée de montagnes. Elle renferme une source dont l'eau est douce et assez abondante pour faire tourner des moulins. On $\mathrm{y}$ remarque encore une autre source, et plus bas une troisième, qui coule avec bruit et qui porte le nom d'Abū Mahlad. Les eaux de ces sources convergent dans la ville et forment le Sahur. Dans la ville de Ghdir, il y a une mosquée et plusieurs marchés bien achalandés. On y trouve beaucoup de fruits qui se vendent bon marché, ainsi que du blé et de la viande. Pour un dirham on achète un quintal de raisins. Ses habitants sont des Hawwāra formant une population de soixante mille âmes ».

14 Mention où il est dit que le site de $\dot{G} a d \bar{r} r$ al-durū' se trouve dans la région de Tiaret ce qui constitue une erreur évidente.

15 Il s'agit peut-être d'une erreur de graphie du mot $r a$ 'îs ou bien alors d'une forme dialectale pour ce terme. 
Al-Idrīsī, 1983 :

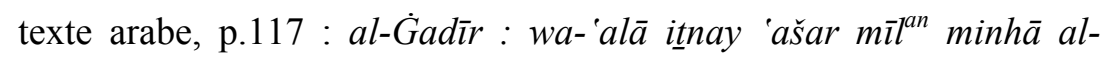
Masīla allatī taqaddama dikruha garb ${ }^{a n}$; wa-l-Masīla fì ard tayyiba wa-fi ğihat al-magrib min madīnat al-Qal'a ; wa-min al-Qal'a waayḍan fi ğihat al-mašriq madīna ${ }^{t}$ muhdata tusammā al-Ġadīr ; wabaynahā wa-bayna al-Qal'a tamāniya ${ }^{t}$ amyāl ; wa-l-Gadìr madīna ${ }^{t}$ hasana wa-ahluhā badw ; wa-lahum mazāri' wa-arḍ̄n mubāraka ;

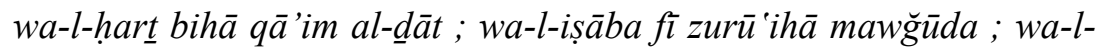
barakāt fì mu'āmalātihim katīira; wa-bayna al-Masīla wa-l-Gadīr țamāniya ${ }^{t}$ 'ašar mīlan.

traduction, pp.109-110 : «Ghdir : à douze milles, à l'ouest de là [la Qal'a] se trouve M'sila qui a déjà été citée. M'sila se situe sur de bonnes terres dans la zone occidentale de la Qal'a. Dans la zone orientale de la Qal'a aussi, il y a une ville récente appelée Ghdir. Entre elle et la Qal'a, il y a huit milles. C'est une belle ville, habitée par des ruraux qui possèdent des exploitations agricoles aux terres fertiles labourées en permanence et donnant de bonnes récoltes. Les transactions qui s'y effectuent sont rentables. Entre M'sila et Ghdir, il y a dix-huit milles ».

\section{Al-Istibșār, 1958 :}

texte arabe, p.167 : madīnat al-Ġadīr : wa-hiya madīna kabīra azaliyya bayna ğibāl, qad ahdaqat bihā, wa-lahā nahr yağtami 'u min al-'uyūn fi mawḍi' dahs yahruğu minhu hādā l-nahr, wa-yusammā nahr Sahur, wa-yamš̄ min hunāka ilā madīnat al-Masīla wa-huwa nahruhā, wa-l-Masīla min bilād al-Zāb [...] wa-bi-qurb madīnat alĠadìr faḥs 'Ağīsa, wa-huwa faḥs madīd katīir al-zar' wa-l-dar' illā annahu sadīd al-bard wa-l-talğ, wa-la-qad dahaltu hāda l-fahs fị zaman al-șayf fa-ra'aytu al-ğalìd yanzilu fihi bi-l-gadw, wa-min amtāal tilka al-bilād : "bard al-balad Ağ̄isa fì l-ṣayf wa-ammā al-šitā' fa-sakarat al-mawt" ; wa- 'indahum al-nīla al-mašhūra.

traduction : « La ville de Ghdir : c'est une grande ville ancienne située au milieu de montagnes qui l'entourent. Il y coule une rivière formée de la confluence de sources dont les eaux se déversent dans un endroit vaseux d'où elle tire son origine ; c'est la rivière appelée Sahur qui se 
dirige ensuite vers M'sila ; quant à M'sila, elle fait partie du Zāb [...]. Proche de Ghdir, il y a la plaine de 'Ağīsa qui est étendue et produit beaucoup de céréales et d'élevage mais où sévissent le froid et la neige. J'ai pénétré dans cette région en saison d'été, et j'y ai constaté de la gelée de bon matin ; aussi y-a-t-il un proverbe sur ce pays : "Du froid qu'il fait à 'Ağīsa, en plein été qu'on juge de ce que doit être l'hiver"; on y trouve de l'indigo très réputé ».

Ibn Ḥammād, 1984 :

texte arabe, p.42: madinnat al-Gidìr.

traduction : «Ville de Ghdir ».

Yāqūt, 1979-1986 :

texte arabe, IV, p.188 : al-Ġadìr : balad aw qarya 'alā nisf yawm min qal 'a ${ }^{t}$ Banī Hammād bi-l-magrib.

traduction : "Ghdir : ville ou village à une demie-journée de la qal'a des Banū Ḥammād en arrivant par l'ouest ».

Idrīs 'Imād al-Dīn, 1985, p.416 : simple mention du site de $\dot{G} a d \bar{r} r$ $W \bar{a} n^{16}$. 
4) 'Aḍna / Bašīlqa / Adna (antique JVSTINIANA ZABI et aujourd'hui Bechilga) ${ }^{17}$

Al-Raqīq, 1990 :

texte arabe, p.11: fa-rahala ilā bilād al-Zāb, fa-sa'ala 'an a'zam madā'inihim qadr ${ }^{a n}$ fa-qālū: madīna yuqālu lahā 'Adña.

traduction : «Puis il voyagea jusqu'au pays du Zāb, et il demanda quelles étaient ses plus grandes villes : ils dirent que c'était la ville appelée 'Adna ».

\section{Al-Bakrī, 1965 :}

texte arabe, p.59: wa-bi-qiblī madīnat al-Masīla mawḍi' yu 'rafu bi-lQibāb fîhi qibāb min bunyān al-awwal wa-'alā maqraba minhā madīna li-l-awwal huribat yuqālu lahā Bašīlqa fìhā ğadwalān min $m \bar{a}$ ' 'ad̆ ğalabahu al-awwal ilayhā yuqālu lahā tārqā-in-wūdā tafsīruhu sāqiyat al-samn.

traduction, p.124 : «Au sud de M'sila, il y a un endroit appelé "les coupoles". On y remarque des voûtes antiques auprès desquelles il y a les restes d'une ville ancienne nommée Bechilga. Ces ruines sont traversées par deux rigoles d'eau douce, dont les conduits sont de

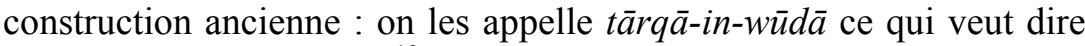
"rigole de beurre fondue" "18".

texte arabe, p.144 : wa-bayna 'ayn al-kattān wa-Adna : nahr Sahur wa-nahr al-nisā' wa-nahr Abī Tawīl wa- 'ayn al-ġazāl.

17 Sur ce site, voir Diehl, 1896, p.254 ; Gsell, 1911, feuille 25, nº 85 ; Lewicki, 1953, p.444; Talbi, 1966, p. 125 ; Cambuzat, 1970, pp.110-113 où il est proposé de situer la ville de $\mathrm{M}$ 'sila au $4^{\mathrm{e}} / \mathrm{X}^{\mathrm{e}}$ siècle à environ quatre kilomètres de Zābī ; idem, 1986, II, pp.21-24 ; Trousset, 1985, p.370 ; Benseddik, 1999, p.94 signale le site de Jvstiniana Zabi sur le limes de la Maurétanie Césarienne ; Matveyev, 1999, p.128; Laporte, 1999, p.213 situant Zabi à la frontière occidentale de la Maurétanie Sitifienne avec la Maurétanie Césarienne, et Benabbès, 2005, pp.478-480.

18 Sur cette locution berbère, voir Chaker, 1981, p.41 et Van Den Boogert, 2000, pp.369, 373. 
traduction, p.276 : «Entre la rivière du lin et Adna, il y a la rivière Sahur, la rivière des femmes, la rivière d'Abū Ṭawīl et la rivière de la gazelle».

Idrīs 'Imād al-Dīn, 1985 :

texte arabe, p.407 : Adna madinat awwaliyya qad huribat.

traduction : «Adna, ville antique qui a été détruite ».

5) Țarfala (antique THAMALLVLA et aujourd'hui Aïn Toumella/Ras el Oued) ${ }^{19}$

Al-Bakrī, 1965 :

texte arabe, p.60 : wa-bi-šarqī madinat al-Gंadīr qarya ${ }^{t}$ awwaliyya yuqālu lahā Tarfala lā tu'addalu bihā qarya wa-hum yaqūlūna : "Ṭarfala țaraf min al-ğanna".

traduction, pp.125-126: «À l'est de la ville de Ghdir, il y a un village antique appelé Țarfala. Ce village n'a pas son pareil dans le monde aussi disent-ils que "Ṭarfala est une portion du Paradis" ».

Ibn Abī Dīnār, 1967 :

texte arabe, p.31 : wa-min Tāğirā ilā Tarfala madīnat al-Sūs al-aqșā masīra šahrayn.

traduction : «De Tāğirā jusqu'à Tarfala, ville du Sous extrême, il y a un parcours de deux mois $»^{20}$.

19 Sur ce site, voir Gsell, 1911, feuille 26, $\mathrm{n}^{\mathrm{o}} 19$; Idris, 1962, II, pp.504-505; Cambuzat, 1986, II, p.212 ; Forstner, 1979, pp.47, 180, 181, 302, 309, 338 ; Gascou, 1982, pp.257-258 sur le site de Thamallula ; T. Kotula, 1991, pp.472475 ; Laporte, 1999, p.213 situant Thamallula à la frontière occidentale extrême de la Maurétanie Sitifienne avec la Maurétanie Césarienne, et Desanges, 2005, p.23 évoque le toponyme romain sous la forme de r(es)p(ublica) Thamallulensium en face du siège épiscopal Thamallumensis. 
6) Ūsağît / Awsağît / Ūsaḥant / Awsaḥant (antique EQVIZETUM et aujourd'hui Ouled Agla (ex-Lecourbe) ${ }^{2 \mathrm{i}}$

Ibn Ḥawqal, 1938-1939 :

texte arabe, I, pp.87-88 : wa-minhā ilā Ūsağ̄it / Awsă̌ìt marhala wahiya qarya fìhā ba 'd hawānìt li-Barbar Kutāma wa-lahā mā' katīira yazra 'ūna 'alayhā.

traduction : «De là jusqu'à Ūsağît / Awsağîit, il y a une étape ; c'est un village où il y a quelques échopes tenues par des Berbères Kutāma ; il y a de l'eau en abondance grâce à laquelle on cultive ».

\section{Al-Idrīsīi, 1983 :}

texte arabe, p.160 : wa-minhā ilā Usahant / Awsahant marhala wahiya qarya li-l-Barbar wa-bihā mā' ğāriya wa-mazāri ' hința wa-šarì'.

traduction : « De là jusqu'à Ūsaḥant / Awsaḥant, il y a une étape, c'est un village berbère où il $\mathrm{y}$ a de l'eau vive et des champs de blé et d'orge $»$.

Ibn Ḥammād, 1984 :

texte arabe, p.43 : wa-hiya (Ūsağìt / Awsağit) bi-safh ğabal al-Qal'a min ǧihat al-šamāl mimmā yalì balad 'Ağ̄isa.

traduction : «Elle (Ūsağît / Awsağît) se situe au pied de la montagne de la Qal'a sur le versant nord qui est proche du pays des 'Ağīsa ».

20 Nous avons pris le parti de relever cette référence mais nous pensons qu'il s'agit en réalité d'un toponyme situé bien loin de notre région d'étude (al-Sūs al$a q \underline{a} \bar{a})$.

21 Sur ce site, voir Gsell, 1911, feuille 15, $\mathrm{n}^{\circ} 91$; Idris, 1962, II, p. 478 ; Forstner, 1979, pp.177, 179, 184 ; Gascou, 1982, pp.256-257 sur le site d'Equizetum ; Cambuzat, 1986, II, pp.19-20, et Laporte, 1999, p.213 situant Equizetum à la frontière occidentale extrême de la Maurétanie Sitifienne avec la Maurétanie Césarienne. 
7) Dakkamā / Dakkama / Dakma : site entre Magra et M'sila ?22

Al-Muqaddasī, 1950 :

texte arabe, pp.4 et $6: w a-a m m \bar{a}$ Ifrīqiya fa-qașabatuhā al-Qayrawān wa-min mudunihā [...] Dakkamā.

traduction, pp.5 et $7:$ : Quant à l'Ifrīqiya, sa capitale est Kairouan, et il y a parmi ses villes [...] Dakkamā ».

\section{Al-Bakrī, 1965 :}

texte arabe, p.54 : wa-minhā ilā madīnat Dakkama wa-hiya 'alā nahr kabīr d̄āt mazāri' wa-masārih.

traduction, p.115 : «De là jusqu'à Degma, situé sur une grande rivière avec des terres cultivées et des pâturages ».

\section{Al-Idrīsīi, 1983 :}

texte arabe, p.160 : wa-minhā ilā Dakma marhala, wa-hiya qarya lahā suq, wa-ahluhā min Kutāma.

traduction, p.147 : «Jusqu'à Dakma, il y une étape, c'est un village avec un marché et ses habitants sont des Kutāma ».

Yāqūt, 1979-1986 :

texte arabe, II, p.459 : Dakma [...] balda bi-l-Magrib min a 'māl Ban̄̄ Hammād.

traduction : « Dakma [...] ville du Maghreb dans les districts des Banū Hammād ». 
8) Tāmasnat / Tāmaslat / Tāmasīt : site non identifié ${ }^{23}$

Al-Muqaddasī, 1950 :

texte arabe, p.4 et p.6:wa-ammā Ifrīqiya fa-qașabatuhā al-Qayrawān wa-min mudunihā [...] Tämasnat.

traduction, p.5 et p.7 : «Quant à l'Ifrīqiya, sa capitale est Kairouan, et il y a parmi ses villes [...] Tāmasnat».

Ibn Ḥawqal, 1938-1939 :

texte arabe, I, p.87 : wa-minhā ilā Tāmasnat qarya wa-sūq li-Kutāma wa-Mazāta wa-lahā ağinna wa-mā' yağrī wa-ābār mu 'ìna marhala.

traduction : «Il y a une étape de là jusqu'à Tāmasnat : c'est un village avec un marché tenu par des Kutāma et des Mazāta ; il y a des jardins, de l'eau qui ruisselle et des puits d'eau courante ».

\section{Al-Bakrī, 1965 :}

texte arabe, p.54 : wa-minhā ilā Tāmaslat wa-hiya madīna ${ }^{t}$ ğalīla li-lzar' wa-l-dar'.

traduction, p.115 : «De là jusqu'à Tāmaslat qui est une ville remarquable par ses céréales et ses troupeaux $»$.

\section{Al-Idrīsī, 1983 :}

texte arabe, p.160 : wa-minhā ilā qarya ${ }^{t}$ Tāmasìt marhala wa-bihā ašğār wa- imārāt.

traduction, p.147 : «De là jusqu'au village de Tāmasīt, il y a une étape et il y a des arbres et des constructions $»^{24}$.

23 Sur ce site, voir Idris, 1962, II, p.478 et Cambuzat, 1986, II, pp. 211-212. Quant à Chaker, 1983, p.134, il signale un Tamasnā comme étant le nom d'une vaste plaine atlantique du Maroc. 
9) Yaksim : site proche de Magra mais non identifié 25 $^{25}$

Al-Bakrīi, 1965 :

texte arabe, p.144 : wa-bi-šarqiyyihā wād̄̄ Maqqara 'alayhi saba' qurā minhā qarya Yaksim wa-zaytuhā ațiyab al-zaytūn.

traduction, p.276 : «À l'est de l'oued Magra, ruisseau en bordure duquel il y a sept villages, dont celui de Yaksim qui fournit une huile avec les meilleures olives $\gg$.

10) Barğalus (antique BVRGVS CELLAS ?) : site proche de Magra $^{26}$

Al-Ya'qūbī, 1892 :

texte arabe, p.351 : wa-minhā ilā hușūn tusammā Barğalus [...].

traduction : « De là jusqu'aux forts appelés Barğalus [...] ».

11) Țalma : site proche de Magra mais non identifié ${ }^{27}$

Al-Ya'qūbī, 1892 :

texte arabe, p.351 : wa-minhā ilā huṣūn tusammā [...] Ṭalma.

traduction : «De là jusqu'aux forts appelés [...] Ṭalma ».

12) Ğayzūr : site proche de Magra mais non identifié ${ }^{28}$

Al-Ya'qūbī, 1892 :

texte arabe, p.351 : wa-minhā ilā hușūn tusammā [...] Ğayzūr.

traduction : « De là jusqu'aux forts appelés [...] Ğayzūr ».

24 Le traducteur du texte arabe rend le terme imārāt par «exploitations agricoles ». En l'absence de plus de précisions, nous préférons maintenir le mot « constructions».

25 Sur ce site, voir Cambuzat, 1986, II, p.146, note 4.

26 Sur ce site, voir Forstner, 1979, pp.192, 197.

27 Sur ce site, voir Forstner, 1979, pp.192, 197.

28 Sur ce site, voir Forstner, 1979, pp.192, 197. 
13) Ăga : site proche de Magra mais non identifié ${ }^{29}$

Al-Ya'qūbī, 1892 :

texte arabe, p.351 : wa-madīnat Ağa wa-hiya 'alā l-ğabal.

traduction : «Et la ville d'Ağa est située sur la montagne ».

14) Arba : site proche de Magra mais non identifie ${ }^{30}$

Al-Ya'qūbī, 1892 :

texte arabe, pp.351-352 : wa-madīnat Arba wa-hiya āhar mudun al$Z \bar{a} b$.

traduction : « Et la ville d'Arba qui est la dernière des villes du Zāb ».

\section{Observations sur les modes de peuplement dans le Hodna occidental}

Les centres de peuplement créés dans les steppes par les Romains ont souvent été peuplés par des militaires et quelques familles originaires de diverses régions du monde méditerrannéen. Sous les Vandales, nous savons par exemple que le souverain Hunéric y envoie des catholiques en exil. Mais en revanche, il y a très peu de données sur la période byzantine. C'est toutefois ce faible apport allogène avec lequel les groupes berbères ont fusionné et constituant cette population souvent connue par le terme de Reum dont nous parlent les sources anciennes et arabes ${ }^{31}$. La conquête musulmane amène dans les centres urbains notamment de nouveaux éléments : orientaux et berbères. Magra est peuplée par les Banū Dabba, des 'Ağam et des Berbères; M'sila, ville de nouvelle fondation, est habitée à la fois par des Arabes et des Berbères venus de zones environnantes. Pour ce qui concerne les campagnes, le géographe al-Ya'qūbī nous donne une

29 Sur ce site, voir Forstner, 1979, p.197.

30 Sur ce site, voir Forstner, 1979, pp.187, 192, 197 ; Matveyev, 1999, p.127.

31 Voir Mattingly \& Hitchner, 1995, pp.189-196 sur les recherches faites en histoire antique dans ce domaine jusqu'en 1995. Pour la période vandale, voir Modéran, 2003, pp.395, 405, 410, 550, 555, 582. 
brève liste de fractions tribales qui, au $3^{\mathrm{e}} / \mathrm{IX}^{\mathrm{e}}$ siècle, sont presque toutes d'origine zénète ${ }^{32}$. Depuis l'Est avec les invasions hilāliennes du $5^{\mathrm{e}} / \mathrm{XI}^{\mathrm{e}}$ siècle et l'Ouest sous la houlette des Almoravides, le Hodna connaît également un renouvellement sensible de son peuplement. La région voit arriver de nouveaux groupes dans le sillage almoravide et hilālien tandis que d'autres disparaissent, transportés de force, chassés ou obligés de se fondre avec les nouveaux arrivants. À partir du $6^{\mathrm{e}} / \mathrm{XII}$ siècle, le mouvement almohade part à la conquête du Maghreb et va étendre ses territoires jusqu'au Hodna et plus loin à l'Est. Cette région est en premier lieu, ainsi que les Ziban de Biskra, soumise à l'autorité des Banū Ațbāğ, de la confédération des Banū Riyāh ${ }^{33}$.

Ces quelques événements que nous venons de résumer vont avoir de sérieuses répercussions sur les structures de l'habitat et l'organisation des communautés rurales ${ }^{34}$. Si l'on se penche maintenant sur le vocabulaire, il est possible de se faire une idée de cette distribution des territoires autour de trois pôles : la structure de peuplement fondée autour d'une entité urbaine, celle mise en place dans le village et celle construite alentour d'une fortification. Le phénomène urbain dans le Maghreb central médiéval est encore le parent pauvre de la recherche si on le compare aux travaux et aux publications réalisés sur le Maghreb occidental et l'Ifrīqiya. Il y a bien, çà et là, quelques notices insérées dans des ouvrages monographiques mais qu'il faut, dans leur immense majorité, reprendre en profondeur ${ }^{35}$. Dans les lignes suivantes, nous voudrions aborder de manière très succinte, la question de la possible confusion qu'il y a entre les concepts de structure urbaine organisée et comprise dans le sens de "ville" (madìna), puis avec l'idée de petit centre urbain

32 Al-Ya'qūbī, 1892, pp.351, 352 ; al-Bakrī, 1965, p.59/124. Sur l'ensemble de ces questions, voir Bahri, 2000, pp.68-69 ; Prévost, 2007, pp.469-475 sur la problématique des derniers chrétiens du Sud tunisien (Afāriqa / 'Ağam).

33 À titre d'exemple, voir Meouak, 2006c, pp.11-14 sur les vicissitudes de la tribu des Banū Zug̉ba dans la zone de Hamza (Bouira) avec les pouvoirs politiques en place durant le Moyen Âge.

34 L'orientaliste hollandais Reinhardt Dozy proposait la définition suivante du terme : « hiṣn, redoute. Village entouré d'une muraille» (Dozy, 1967, I, p.297).

35 Notamment dans les ouvrages classiques de Brunschvig, Golvin, Idris, etc. Si des travaux récents existent sur les problèmes posés dans notre étude pour le Maghreb central, nous reconnaissons bien volontiers qu'il nous a été impossible de les localiser jusqu'à aujourd'hui. 
(madīna ${ }^{t}$ șàìra) et enfin en tant que village (qarya) afin de désigner un même site à travers la documentation arabe du Moyen Âge. Pour cela, nous centrerons notre démarche sur le cas de Magra. Notons tout d'abord la variété du vocabulaire avec laquelle les écrivains arabes désignèrent le site de Magra : al-Ya'qūbī : madīna autour de laquelle il y a de nombreuses fortifications (lahā hușūn kațīra) ; Ibn Hawqal : manzil possédant un poste de guet (manzil fìhi ayḍan marșad) ; alMuqaddasī : madīna; al-Bakrī : madīna avec un territoire important (balad kabìr) ; al-Idrīsī : madīna ${ }^{t}$ șagì̄ra ; Yāqūt : madīna ; Ibn Haldūn : qarya ; Idrīs 'Imād al-Dīn : maw dị' ; Ibn Maryam : qarya ; Ibn al-Qāộ̄ : qarya ; al-Maqqarī : qarya.

Cette liste avait pour simple objectif de mettre en relief le flottement existant dans la manière de désigner un même site. Ces désignations montrent qu'un lieu est considéré, tour à tour, comme une ville, une grosse bourgade, un village, voire l'équivalent d'un hameau. Dès lors, cette terminologie appelle plusieurs remarques. En premier lieu, il y a la question de la chronologie des textes qui est fondamentale puisqu'elle peut donner des éléments relatifs à la perception du paysage et du vocabulaire permettant ainsi de mesurer les désignations des lieux à travers les siècles. Cette séquence du temps évoque bien entendu les modifications de la nomenclature générale mais elle peut être également un excellent indicateur des changements structurels et une allusion, même vague, aux aléas politiques et sociaux ayant marqué le développement de tel ou tel site. En outre, il ne faut pas perdre de vue que les auteurs orientaux (alYa'qūbī, Ibn Ḥawqal, al-Muqaddasī, Yāqūt et Idrīs 'Imād al-Dīn) avaient, à n'en pas douter, une idée différente des paysages modelant les régions par rapport à leurs homologues occidentaux. Ensuite, il est nécessaire de signaler que les éléments géomorphologiques sont d'une extrême importance et ils doivent être pris en compte. En effet, les paysages et les territoires orientaux (Égypte, Irak, Syrie, etc.) ne sont pas totalement comparables à ceux rencontrés au Maghreb : un site oriental peut être compris comme étant une qarya selon qu'il se trouve en un milieu physique précis et le lieu occidental sera quant à lui perçu différemment avec une autre appellation ; le milieu montagnard oriental est assez différent de celui situé au Maghreb, etc. Enfin, nous pensons qu'il est tout à fait utile de prendre en considération la qualité et la quantité des interventions des groupes humains dans la 
modélation des paysages et cela en fonction de la situation politicoéconomique d'une zone donnée. Outre ce qui vient d'être signalé, rappelons que les écrivains arabes rédigèrent leurs ouvrages à des époques précises et celles-ci correspondaient sans doute à des changements de morphologie d'un site donné comme celui de Magra. Ce dernier avait d'abord été, à la lumière de la documentation arabe, une ville, puis une village et enfin un simple lieu-dit car sa situation géographique, économique et politique s'était vue modifier au fil du temps.

À la vue de ce qui vient d'être dit, il semble plus que jamais nécessaire de prendre en compte les méthodes de l'archéologie comme outil indispensable pour qui veut connaître la réalité des choses. Mais qu'entendons-nous par réalité des choses ? Nous voulons ici parler du fait de mettre à jour quelques évidences matérielles, vérifiées si possible dans la documentation écrite, et qui prouveraient la possible existence de véritables structures de peuplement rural en qarya et his $n^{36 .}$ Mais contentons-nous, pour l'heure, de quelques brèves remarques sur les deux vocables suggérés. La qarya (pluriel $q u r \bar{a})$ correspond à un mot en étroite relation avec les questions de peuplement en milieu rural. La qarya constitue un exemple pertinent de structure et d'organisation des collectivités rurales installées dans la région de M'sila. Les textes arabes utilisés offrent une signification générale assez vague pour désigner les localités rurales. En outre, cette imprécision est accompagnée par l'idée que les qurā entretiennent une relation de dépendance avec les sites fortifiés, ou bien alors avec les hușūn qui représenteraient ainsi l'État. Pour le cas de l'Ifrīqiya au bas Moyen Âge, il serait possible d'observer l'existence d'au moins deux types de villages : le petit hameau et le gros bourg avec par exemple le terme manzil et l'expression qarya ${ }^{t}$ 'azìma. Pour ce qui réfère au hiṣn (pluriel hușūn), on peut dire qu'il s'agit du terme le plus caractéristique pour signifier un pôle d'habitats fortifiés et il incarne la difficulté rencontrée à l'heure de cerner avec précision une structure

36 C'est ce que nous tentons de faire, en partie, dans un ouvrage en cours de rédaction sur la région de Biskra et provisoirement intitulé Entre montagne et désert. Géographie, peuplement et territoires de Biskra et ses oasis au Moyen Age. 
fortifiée ${ }^{37}$. Centre du pouvoir étatique, du pouvoir territorial avec un petit groupe d'individus exerçant une autorité sur les qurā environnantes ou encore refuge pour les habitants de ces villages contre les déprédations des rebelles et des bandits en quête de butin ou des armées gouvernementales? Si l'on se penche sur la terminologie des forteresses rurales du Maghreb central d'après les sources arabes médiévales, on a une impression de confusion. Cependant, l'apparente liberté dont témoignent les écrivains arabes en se référant aux divers types de fortification cache, sans doute, des différences sensibles parmi les sites fortifiés. Cette dernière réflexion trouve une excellente illustration lorsque l'on sait que pour la zone située entre la célèbre qal 'a des Banū Ḥammād et Bougie, non loin de M'sila, al-Idrīsī utilise les mots hiṣn et qașr qui recouvrent des réalités morphologiques et utilitaires diverses selon que l'on se trouve en plaine ou en montagne, en bordure de rivière ou en zone plus aride ${ }^{38}$.

\section{Conclusions ouvertes et questions connexes}

En guise de " point à la ligne » à notre étude, nous voudrions nous arrêter sur une problématique complexe, mais qu'il faudra aborder dans de futures recherches, et qui a diffusée l'idée que le Maghreb médiéval n'était qu'une entité géographique où le mercantilisme parasitaire était généralisée ${ }^{39}$. Il semblerait qu'à la lumière de quelques données déjà mises à jour sur les conditions agricoles du Hodna occidental nous soyons plutôt confrontés à une société relativement dynamique, productrice de nombreux biens et en outre exportatrice de plusieurs denrées. L'historiographie arabe montrerait que les productions agricoles étaient, semble-t-il, importantes au point où des surplus auraient parfois servi de base au développement de l'artisanat spécialisé et à la croissance urbaine au Maghreb central. Même si les conditions étaient différentes d'une zone à une autre, en

37 Voir par exemple Hassen, 2000, pp.235-236, 239-243 pour l'étude du vocabulaire de la fortification au Maghreb oriental à la fin du Moyen Âge.

38 Meouak, 2006a, pp.183-184.

39 Sur ces questions, on lira Megherbi, 1971, pp.129-154 qui propose une critique intéressante des courants historiographiques qui ont soutenu l'idée selon laquelle Ibn Haldūn opposait irréductiblement les nomades aux sédentaires. 
plaines ou en montagnes, il est difficile de soutenir l'idée selon laquelle les activités agricoles et l'économie rurale avaient été complètement séquestrées par les pouvoirs politiques en place, et qui par conséquent auraient débouché sur l'existence de deux mondes opposés $^{40}$ : le rural fossilisé et l'urbain dynamique car déprédateur du monde rural. Certes le facteur politique et le fait tribal ont parfois joué un rôle négatif dans le difficile décolage économique de certaines régions mais il n'en reste pas moins que l'économie était variée et possédait une remarquable capacité de production.

Région frontière, zone d'influence ou marche pendant plus d'un millénaire, région de passage entre les hautes steppes algéromarocaines et les hautes plaines de l'Ifrīqiya, entre le Sahara oriental et les marches du Tell, zone de nomadisme traversée par les hommes et les animaux, et habitée aussi par des populations en grande partie pastorales, le Hodna a connu, depuis l'Antiquité, et surtout depuis le $5^{\mathrm{e}} / \mathrm{XI}^{\mathrm{e}}$ siècle, un intense mouvement de va-et-vient de groupes humains divers et variés. Après la chute de Rome, le Hodna connaît des conditions historiques nouvelles : deux périodes de troubles causées par des invasions vandales $\left(\mathrm{V}^{\mathrm{e}}\right.$ siècle) et par des conquêtes arabes $\left(1^{\mathrm{er}} / \mathrm{VII}^{\mathrm{e}}-2^{\mathrm{e}} / \mathrm{VIII}^{\mathrm{e}}\right.$ siècle $)$ alternent avec deux moments de redressement dues aux Byzantins $\left(\mathrm{VI}^{\mathrm{e}}-\mathrm{VII}^{\mathrm{e}}\right.$ siècle) d'une part et aux diverses dynasties musulmanes installées en Ifrīqiya d'autre part. Malgré cela, le Hodna, comme les Ziban, continue à jouer un rôle de région frontière, ou au moins de marche militaire, administrative et économique face aux steppes et aux déserts échappant à un quelconque contrôle politique ${ }^{41}$.

On soulignera également du point de vue strictement historiographique que dans la littérature arabe médiévale, la coexistence du couple terre fertile / terre stérile présume souvent des véritables spécificités du terroir. La première est celle de l'abondance et des ressources vivrières inépuisables, une sorte de terre promise où chacun peut subvenir à ses moyens alimentaires par exemple. La

40 Voir Meouak, 2009, pp.128-134 offrant certains résultats invitant à poursuivre l'enquête sur les rapports entre monde rural et milieu urbain à la lumière des productions agricoles et artisanales.

41 Diehl, 1896, pp.250-254; Modéran, 2003, pp.541-561. Voir Mattingly \& Hitchner, 1995, pp.171-174 sur les recherches faites en histoire antique sur ces thèmes jusqu'en 1995. 
seconde est souvent décrite en termes négatifs: terre ingrate, désertique et aride, incapable de produire la moindre once de verdure. Les modèles donnés par les géographes arabes de cette époque, comme les régions périphériques des grands déserts, les steppes, certaines régions montagneuses sont des types révélateurs de la parcimonie de la nature et de sa dureté. Cela dit, il faut bien reconnaître que cette même dureté transparaît assez bien dans les sources arabes. Elle est alors le témoignage que les individus ont souvent essayé de domestiquer leur environnement avec plus ou moins de succès malgré les cycles connus de famine et de cataclysmes naturels au cours de l'histoire du Maghreb. C'est d'ailleurs bien grâce à ces informations sur les désastres naturelles et autres méfaits qu'il est possible d'analyser partiellement, par exemple, l'espace rural comme un ensemble de lieux différenciés par l'usage tout en tenant compte des données climatiques ${ }^{42}$. Les divers milieux écologiques sont en effet distingués en fonction de leur capacité à produire des denrées agricoles en abondance ou non. La description des espaces ruraux laisse apparaître que les campagnes sont considérées comme le prolongement du jardin mais à l'échelle du terroir. L'étendue de l'empire musulman et la richesse culturelle qu'il englobe ont permis la circulation dans cet immense territoire de nouvelles idées, de nouveaux procédés techniques, de nouvelles façons d'organiser l'espace. Les influences indienne, persane ou même chinoise ont été déterminantes dans la création des paysages postérieurs. Il est donc juste de reconnaître que ces nouveaux horizons ont joué un rôle capital sur l'imaginaire collectif et la représentation paysagère en milieu musulman.

\section{Bibliographie}

\section{Sources arabes}

Al-Bakrī (mort en 487/1094), Description de l'Afrique septentrionale, éd. et trad. M. Mac Guckin De Slane, Alger, 1911/1913.

42 Voir un excellent exemple de ce qui peut être fait dans ce sens en consultant Rouvillois-Brignol, 1986, pp.35-40. 
Ibn 'Abd Rabbihi al-hafìd (vers 587/1191), Kitāb al-istibṣār fí 'ağ $\bar{a}$ 'ib al-amșār, intro. et éd. S.Z. 'Abd al-Ḥamīd, Alexandrie, 1958.

Ibn Abī Dīnār (mort en 1092/1681 ou 1110/1698), al-Mu'nis fí ahbā̄r Ifrīqiya wa-Tūnis, éd. M. Šammām, Tunis, 1967.

Ibn ㅂaldūn (mort en 808/1406), Ta'rīh Ibn Haldūn al-musammā Dīwān al-mubtada' wa-l-habar fì ta'rīh al- 'Arab (wa-l- 'A ğam) wal-Barbar wa-man 'āsarahum min dâwī l-ša'n al-akbar, éd. $\underline{\mathrm{H}}$. Šahāāa et revue par S. Zakkār, Beyrouth, 2000-2001, 8 vol.

Ibn Ḥammād (mort en 628/1231), Ahhbār mulūk Ban̄̄ 'Ubayd wasìratihim, éd. Ğ.A. al-Badawī, Alger, 1984.

Ibn Hawqal (vers 378/988), Kitāb șūrat al-ard, éd. J.H. Kramers, Leyde, 1938-1939, 2 tomes en 1 vol.

Ibn Maryam (mort en 1011/1602-1603), Al-Bustān fì dikr al-awliyā' wal- 'ulamā' bi-Tilimsān, éd. M. Bencheneb, Alger, 1908.

Ibn al-Qāḍ̄ī (mort en 1025/1616), Dayl wafayāt al-a 'yān al-musammā Durrat al-hiğāl fì asmā' al-riğăl, éd. M. al-Ahmadī Abū 1-Nūr, Le Caire - Tunis, 1970-1972, 3 vol.

Ibn Rašīq al-Qayrawānī (vers 456/1064), Unmū da ğ al-zamān fì šu 'arāa' al-Qayrawān, éd. M. al-'A. al-Mațwī \& B. al-Bakkūš, Beyrouth, 1991.

Al-Idrīsī (vers 560/1165), Le Magrib au $6^{e}$ siècle de l'hégire (12 ${ }^{e}$ siècle après $J$-C.) texte arabe établi et traduit en français d'après Nuzhat almuštāq , éd. et trad. M. Hadj-Sadok, Alger, 1983.

Idrīs 'Imād al-Dīn (mort en 872/1468), Uyūn al-aḥbār fí funūn al-ātầr,

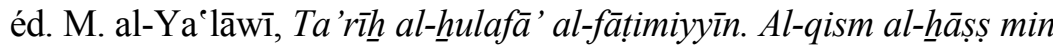
Kitāb 'uyūn al-ahbbār, Beyrouth, 1985.

Al-Maqqarī (mort en 1041/1631), Nafh al-țīb min giuṣn al-Andalus alrațīb wa-dikr wazìrihā Lisān al-Dīn Ibn al-Hațīb, éd. I. 'Abbās, Beyrouth, 1988, 8 vol.

Al-Muqaddasī (vers 380/990), Description de l'Occident musulman au $I V^{e}=X^{e}$ siècle. Extrait du Kitāb Ahsan al-taqāsìm fì ma'rifat alaqālìm, éd. et trad. Ch. Pellat, Alger, 1950. 
Al-Raqīi (première moitié du $5^{\mathrm{e}} / \mathrm{XI}^{\mathrm{e}}$ siècle), Ta'rīh Ifrìqiya wa-l-Magrib, éd. 'A. 'A. al-Zīdān et 'I.D. 'Umar Mūsā, Beyrouth, 1990.

Al-Ya'qūbī (vers 277/891), Kitāb al-buldān, éd. M.J. de Goeje, Leyde, 1892.

Yāqūt al-Rūmī (mort en 626/1229), Mu'ğam al-buldān, éd. de Beyrouth, 1979-1986, 5 vol.

Ouvrages et articles de références

Bahri, F. (2000), "Les 'Adjam al-balad : une minorité sociale d'origine autochtone en Ifrîqiyya aghlabide (III $/ \mathrm{IX}^{\mathrm{e}}$ siècle)", dans $\mathrm{H}$. Bresc et C. Veauvy (dir.), Mutations d'identités en Méditerranée, Saint Denis, pp.67-84.

Baradez, J. (1949), Fossatum Africae. Recherches aériennes sur l'organisation des confins sahariens à l'époque romaine, Paris.

Benabbès, A. (2005), "Les premiers raids arabes en Numidie byzantine : questions de toponymie", dans $\mathrm{Cl}$. Briand-Ponsart (dir.), Identités et cultures dans l'Algérie antique, Rouen, pp.459-492.

Bencheneb, S. (1968), "Massily - Masila ?", Revue d'histoire et de civilisation du Maghreb, 5, pp.12-15.

Benseddik, N. (1999), "Septime Sévère, P. Aelius Peregrinus Rogatus et le limes de Maurétanie Césarienne", dans C. Lepelley et X. Dupuis (éds.), Frontières et limites géographiques de l'Afrique du Nord antique. Hommage à Pierre Salama, Paris, pp.89-107.

Boogert, N. Van Den (2000), "Medieval Berber orthography", dans S. Chaker et A. Zaborski (éds.), Études chamito-sémitiques. Mélanges offerts à Karl-G. Prasse, Paris-Louvain, pp.357-377.

Brunschvig, R. (1940/1947), La Berbérie orientale sous les Hafșides des origines à la fin $d u X V^{e}$ siècle, Bordeaux-Paris, 2 vol.

Cambuzat, P.-L. (1970), "Note sur un toponyme du Zāb au Moyen Âge : Adna - Arba - Azba ?", Revue d'histoire et de civilisation du Maghreb, 8, pp.110-113. 
Cambuzat, P.-L. (1986), L'évolution des cités du Tell en Ifrîkiya du $V_{I I}^{e}$ au $X I^{e}$ siècle, Alger, 2 vol.

Chaker, S. (1981), "Données sur la langue berbère à travers les textes anciens : la Description de l'Afrique Septentrionale d'Abou Obeïd elBekri", Revue de l'Occident musulman et de la Méditerranée, XXXI/1, pp.31-46.

Chaker, S. (1983), "La langue berbère à travers l'onomastique médiévale : el-Bekrî", Revue de l'Occident musulman et de la Méditerranée, XXXV/1, pp.127-144.

Chapoutot-Rémadi, M. (1980), "Fronte sahariano e fronte mediterraneo", Hinterland, 15-16, pp. 10-21.

Dachraoui, F. (1981), Le Califat fatimide au Maghreb, 296-362/909973. Histoire politique et institutions, Tunis.

Desanges, J. (2005), "Pour une enquête phonétique sur la toponymie de l'Afrique du Nord antique", dans A.M. Di Tolla (a cura di), Studi Berberi e Mediterranei. Miscellanea offerta in onore di Luigi Serra, dans Studi Magrebini, nuova serie, III, pp.19-27.

Despois, J. (1942), "La bordure saharienne de l'Algérie orientale", Revue africaine, 86, pp.196-219.

Despois, J. (1953), Le Hodna (Algérie), Paris.

Despois, J. (1958), L'Afrique du Nord, Paris.

Diehl, Ch. (1896), L'Afrique byzantine. Histoire de la domination byzantine en Afrique (533-709), Paris.

Dozy, R. (1967), Supplément aux dictionnaires arabes, Leyde-Paris, 2 vol.

Forstner, M. (1979), Das Wegenetz des Zentralen Magreb in islamischer Zeit. Ein Vergleich mit dem antiken Wegenetz, Wiesbaden. 
Gascou, J. (1982), "La politique municipale de Rome en Afrique du Nord. De la mort d'Auguste au III $^{\mathrm{e}}$ siècle (III. Maurétanie Sitifienne)", dans H. Temporini (hrsg.), Aufstieg und Niedergang der römischen Welt. Politische Geschichte (Provinzen und Randvölker [Forts.], Berlin-New York, pp.254-259.

Golvin, L. (1957), Le Magrib central à l'époque des Zirides. Recherches d'archéologie et d'histoire, Paris.

Gsell, S. (1911), Atlas archéologique de l'Algérie, Alger-Paris.

Ḥasan, M. (1999), Al-madīna wa-l-bādiya bi-Ifrīqiyya fì l- 'ahd al-hafșī, Tunis, 2 vol.

Hassen, M. (2000), "Villages et habitations en Ifriqiya au bas Moyen Âge. Essai de typologie", dans A. Bazzana et É. Hubert (dir.), Castrum 6. Maisons et espaces domestiques dans le monde méditerranéen au Moyen Âge, Rome - Madrid, pp.233-244.

Idris, H.R. (1962), La Berbérie orientale sous les Zīrīdes, $X^{e}-X I I^{e}$ siècles, Paris, 2 vol.

Kehoe, D.P. (1988), The Economics of Agriculture on Roman Imperial Estates in North Africa, Göttingen.

Kotula, T. (1991), "Thamallula, municipium et castellum”, dans Actes $d u I V^{e}$ Colloque international sur l'histoire et l'archéologie de l'Afrique du Nord (Strasbourg, 1988), tome II : L'armée et les affaires militaires, Paris, pp.471-477.

Kurio, H. (1973), Geschichte und Geschichtsschreiber der 'Abd alWädiden (Algerien im 13.-15. Jahrhundert). Mit einer Teiledition des Nażm ad-durr des Muhammad b. 'Abd al-Ğalīl at-Tanasī, Fribourg.

Laporte, J.-P. (1999), "La limite entre les Maurétanies Césarienne et Sitifienne", dans C. Lepelley et X. Dupuis (éds.), Frontières et limites géographiques de l'Afrique du Nord antique. Hommage à Pierre Salama, Paris, pp.213-219. 
Lengrand, D. (2005), "Langues en Afrique antique", dans Cl. BriandPonsart (dir.), Identités et cultures dans l'Algérie antique, Rouen, pp.119-25.

Lewicki, T. (1953), "Une langue romane oubliée de l'Afrique du Nord. Observations d'un arabisant", Rocznik Orientalistyczny, XVII, pp.415-480.

Massiéra, P. (1974), "M'sila du $\mathrm{X}^{\mathrm{e}}$ au $\mathrm{XV}^{\mathrm{e}}$ siècle", Les Cahiers de Tunisie, XXII/85-86, pp.177-207.

Mattingly, D.J. \& Hitchner, R.B. (1995), "Roman Africa: an Archaeological Review", Journal of Roman Studies, LXXXV, pp.165-213.

Matveyev, V.W. (1999), "États périphériques de l'Afrique du Nord du $\mathrm{VIII}^{\mathrm{e}}$ au IX ${ }^{\mathrm{e}}$ siècles", dans W. Madelung, Yu. Petrosyan, H. Waardenburg-Kilpatrick, A. Khalidov, E. Rezvan (eds.), Proceedings of the $17^{\text {th }}$ Congress of the UAEI, St. Petersburg, pp.125-133.

Megherbi, A. (1971), La pensée sociologique d'Ibn Khaldoun, Alger.

Meouak, M. (2006a), "Fortifications, habitats et peuplement entre Bougie et la Qal'a des Banū Hammād : les données du géographe al-Idrīsī (ob. 560/1165)", Mélanges de la Casa de Velázquez, nouvelle série, 36/I, pp.173-193.

Meouak, M. (2006b), "Langue arabe et langue berbère dans le Maghreb médiéval : notes de philologie et d'histoire", Al-Andalus Magreb, 13, pp.329-335.

Meouak, M. (2006c), "Territoires, tribus et pouvoirs dans le Maghreb central au Moyen Âge : le site de Ḥamza et les Banū Zug̈ba", Acta Orientalia, 67, pp.5-18.

Meouak, M. (2008), "Langue et toponymie berbères dans les sources hagiographiques du Maghreb médiéval : l'exemple des Da'āmat alyaqīn fì za 'āmat al-muttaqīn d'al-'Azafī (m. 633/1236)", Rocznik Orientalistyczny, LXI/1, pp.56-72. 
Meouak, M. (2009), "Le Hodna occidental entre régions méditerranéennes et plaines désertiques : organisation des terroirs, communautés rurales et productions agricoles au Moyen Âge", Revue des mondes musulmans et de la Méditerranée, numéro spécial : "Le monde rural dans l'Occident musulman médiéval", 126, pp.117-139.

Meouak, M. (2010), "Retour sur la langue berbère au Moyen Âge à la lumière des géographes al-Bakrī et al-Idrīsī”, Études et documents berbères, 29-30, pp.193-227.

Modéran, Y. (2003), Les Maures et l'Afrique romaine (IV -VII siècle), Rome.

Pentz, P. (2002), From Roman Proconsularis to Islamic Ifrīqiyah, Göteborg.

Prévost, V. (2007), "Les dernières communautés chrétiennes autochtones d'Afrique du Nord", Revue de l'histoire des religions, 224/IV, pp.461-483.

Rouvillois-Brignol, M. (1986), "Quelques remarques sur les variations de l'occupation du sol dans le Sud-Est algérien", dans Histoire et archéologie de l'Afrique du Nord. Actes du III colloque international, réunis dans le cadre du $110^{e}$ congrès national des sociétés savantes (Montpellier, 1-5 avril 1985), Paris, pp.35-53.

Souidi, Dj. (1996), Généalogie et pouvoir au Maghreb du II au $V_{I I} / V I I I^{e}$ au XIII ${ }^{e}$ siècle, Villeneuve d'Ascq.

Talbi, M. (1966), L'émirat aghlabide, 184-296/800-909. Histoire politique, Paris.

Trousset, P. (1985), "Les "fines antiquae" et la reconquête byzantine en Afrique", dans Histoire et Archéologie de l'Afrique du Nord, II colloque international (Grenoble, 5-9 avril 1983), dans B.A.C.T.H.S., n.s., 19 B, pp.361-376.

Valérian, D. (2006), Bougie, port maghrébin, 1067-1510, Rome. 